\title{
Development and validation of a simple spectrophotometric method for quantification of chloride in polymeric materials
}

- Huynh Minh Chau

- Nguyen Thao Nguyen

- Vo Dinh Thien Vu

- Nguyen Anh Mai

University of Science, VNU-HCM

(Received on December $12^{\text {th }} 2014$, accepted on August $12^{\text {th }} 2015$ )

\section{ABSTRACT}

A simple analytical method was calibration curve was constructed from 0.5 to developed for determination of chloride content in polymeric materials. The procedure comprises of two steps, the dissolution of the polymer by alkaline fusion followed by indirect spectrophotometric analysis of the chloride based on the absorption at $460 \mathrm{~nm}$ of $\mathrm{Fe}(\mathrm{SCN})^{2+}$, a product of the reaction between chloride ion and a mixture of mercury (II) thiocyante and ferric ion. A non-linear 20 ppm with $R^{2}=0.9991$; the limit of detection and quantitation were of 0.325 and $1.083 \mathrm{ppm}$, respectively. The recovery of the whole procedure was higher than $92.9 \%$ with a RSD $2.4 \%$. The developed procedure was applied to animated poly(divinylbenzene-co-vinyl benzyl chloride) in order to investigate the extent of amination of the base material.

Key words: Polymer, alkaline fusion, indirect spectrophotometric analysis, chloride ion, mercury (II) thiocyante, ferric ion.

\section{INTRODUCTION}

Many polymeric materials containing active chloride have been used as intermediate products for introducing a number of functional groups for various applications $[1,2]$. Therefore, methods have been developed to analyze chloride e.g. XPS [3], combustion and colorimetric method [4]. However, they cannot accurately determine the chloride content in a wide concentration range, especially at low levels of chloride. In this work, the chloride determination method was developed including two steps, (1) the dissolution of the

polymer by alkaline fusion and (2) an indirect spectrophotometric analysis of the chloride by measuring absorbance of $\mathrm{Fe}(\mathrm{SCN})^{2+}$ complex, a product of the reaction between chloride ion and a mixture of $\mathrm{Hg}(\mathrm{SCN})_{2}$ and $\mathrm{Fe}^{3+}$.

\section{EXPERIMENT}

Materials and equipment

Sodium carbonate, sodium hydroxide, nitric acid, 
ethanol, ammonium ferric sulfate, and mercury (II) thyocyanate were analytical grade and purchased from Merck (Germany). Cross-linked polystyrene materials which contain various levels of chloride were synthesized based on the procedure of our previous work [5].

Nickel bowl and furnace (Nabertherm) which can heat up to $900^{\circ} \mathrm{C}$ was used in alkaline fusion step. UV-1800 spectrophotometer (Shimadzu) was used to obtain the absorbance of samples in analysis step.

\section{Sample preparation}

$0.1000 \mathrm{~g}$ of polymeric material powder (particle size is less than $74 \mu \mathrm{m}$ ) was mixed with $0.50 \mathrm{~g} \mathrm{Na}_{2} \mathrm{CO}_{3}$ and $1.00 \mathrm{~g} \mathrm{NaOH}$. The mixture of sample and alkaline agents in a $\mathrm{Ni}$ bowl were slowly heated in a hot plate for $\sim 2$ hours until the powder mixture became dark brown and smoke emission stopped, the fusion was continued at $300{ }^{\circ} \mathrm{C}$ for 1 hour in a furnace, and the temperature was slowly increased to $450{ }^{\circ} \mathrm{C}\left(2.5^{\circ} \mathrm{C} / \mathrm{min}\right)$, held in 1 hour, finally reached to $600{ }^{\circ} \mathrm{C}\left(2.5^{\circ} \mathrm{C} / \mathrm{min}\right)$ and kept for 3 hours. The resulting white ash was dissolved with water in $100 \mathrm{~mL}$ volumetric flask adjusting $\mathrm{pH}$ to 2 by nitric acid.

In order to validate the sample preparation process, known amount of chloride was added to of the blank material (poly (styrene-co-divinyl benzene)) and this mixture underwent an identical analytical process.

\section{Spectrophotometric analysis}

Aliquots of sample solutions were pipetted to $25 \mathrm{~mL}$ volumetric flask containing $2.00 \mathrm{~mL}$ of $0.25 \mathrm{M}\left(\mathrm{NH}_{4}\right) \mathrm{Fe}\left(\mathrm{SO}_{4}\right)_{2}$ in $9 \mathrm{M} \mathrm{HNO}_{3}$ and $2.00 \mathrm{~mL}$ of saturated $\mathrm{Hg}(\mathrm{SCN})_{2}$ in ethanol. After 10 minutes, the absorbance of the sample solutions was measured at the wavelength of $460 \mathrm{~nm}$.

\section{Method validation}

To evaluate the method accuracy which comprises precision and trueness, the chloride standards with various levels were added to the blank polymer before sample preparation step; then they were processed and analyzed in the same procedure [6]. The recoveries, H (\%), were calculated using equation (1):

$$
H=\frac{C_{1}}{C_{2}} \times 100 \%
$$

Where: $C_{1}$ and $C_{2}$ are the added and the found concentrations of chloride by the method.

The precision of the method was assessed by replicate measurement of 3 samples having identical chloride contents.

Limit of detection (LOD) and limit of quantitation (LOQ) were determined by measuring the absorbance of 21 blank samples and calculated using the following equations:

$$
A_{\text {LOD }}=\bar{A}_{\text {blank }}+3.3 \sigma ; A_{\text {LOQ }}=\bar{A}_{\text {blank }}+10 \sigma
$$

$$
L O D=-\frac{b}{2 c}+\sqrt{\left(\frac{b}{2 c}\right)-\frac{a-A_{L O D}}{c}}
$$

$$
L O Q=-\frac{b}{2 c}+\sqrt{\left(\frac{b}{2 c}\right)}-\frac{a-A_{L O Q}}{c}
$$

Where $a, b, c$ are coefficients of the nonlinear calibration curve: $\mathrm{y}=\mathrm{a}+\mathrm{bx}+\mathrm{cx}^{2}$ and $\sigma$ is a standard deviation of 21 blank samples.

\section{Determination chloride content in real samples}

The chloride levels of 11 cross-linked polystyrene which were used in an amination process were determined by the developed method. 


\section{RESULTS AND DISCUSSION}

\section{Investigation of fusion conditions}

Alkaline fusion is one of the most popular methods using for dissolution solid polymeric materials in polymer additive analysis [7]. Mixture of $\mathrm{NaOH}$ and $\mathrm{Na}_{2} \mathrm{CO}_{3}$ were used as alkaline agents, the ratio of $\mathrm{NaOH}$ :polymer and $\mathrm{Na}_{2} \mathrm{CO}_{3}$ : polymer were of 10:1 and 5:1, respectively, while varying time and temperature program of the fusion process. In the first attempt the fusion was performed immediately in the furnace at $600{ }^{\circ} \mathrm{C}$ (the temperature rate was $10^{\circ} \mathrm{C} / \mathrm{min}$ from room temperature). This approach was failed since the condition was too harsh to prevent the mixture from bubbling over the Ni bowl. Thus, heating the mixture at a low temperature $\left(\sim 300^{\circ} \mathrm{C}\right)$ on a hot plate was carried out for 2 hours before slowly increased to $600{ }^{\circ} \mathrm{C}$ in the furnace.

\section{Investigation of spectrophotometric analysis}

The reaction between chloride ion and mixture of reagents consisting of $\mathrm{Hg}(\mathrm{SCN})_{2}$ and $\mathrm{Fe}^{3+}$ results in the formation of $\mathrm{Fe}(\mathrm{SCN})^{2+}$ complex, which has the maximal absorption at 460 nm (Fig.1).

$\mathrm{Hg}\left(\mathrm{SCN}_{2}+2 \mathrm{Fe}^{3+}+2 \mathrm{Cl} \rightarrow \mathrm{HgCl}+2 \mathrm{Fe}\left(\mathrm{SCN}^{2+}\right.\right.$

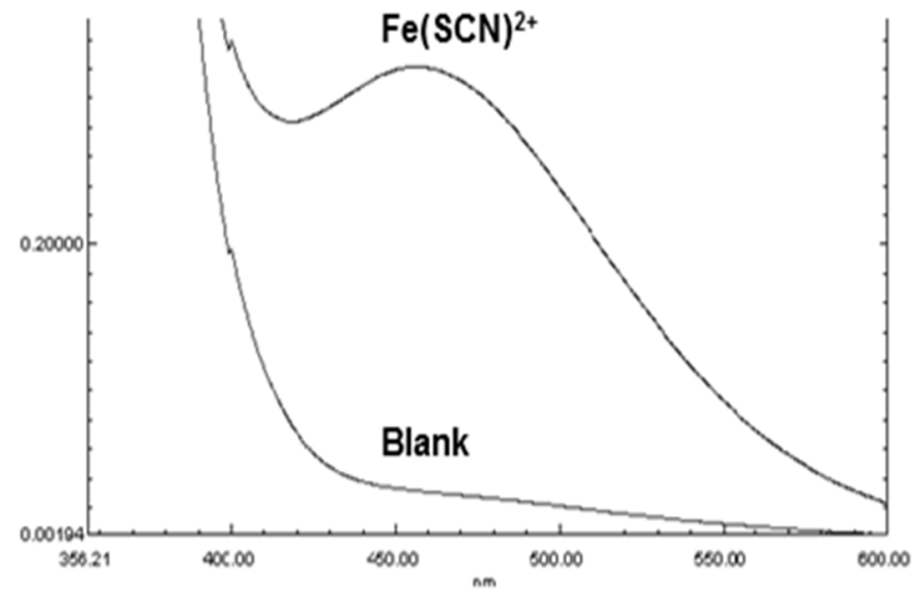

Figure 1. Spectra of $\mathrm{Fe}(\mathrm{SCN})^{2+}$ complex and the reagent blank

The standard curve performed from 1 to 20 ppm, every standard solution was carried out 5 times to get good reproducibility. The result was $2^{\text {nd }}$ order non-linear standard curve with $\mathrm{R}^{2}=$ 0.9991 (5)

$$
Y=0.01878+0.04107 x-0.00075 x^{2}
$$

\section{Method validation}

Limit of detection and quantitation (LOD and $L O Q$ )

The LOD and LOQ of the analytical method were estimated by measuring the absorbance of 21 blank samples and calculated using equation 2 and 3 (Table 1).

\section{Trang 154}


Table 1. LOD and LOQ of the method for determination of the chloride content

\begin{tabular}{|l|l|l|l|l|l|}
\hline $\bar{A}_{\text {blank }}$ & $\sigma$ & $A_{\text {LOD }}$ & ALOQ $_{\text {LOQ }}$ & LOD (ppm) & LOQ (ppm) \\
\hline 0.0118 & 0.0061 & 0.032 & 0.073 & 0.325 & 1.359 \\
\hline
\end{tabular}

The LOD concentration was of $0.325 \mathrm{ppm}$ that was lower than the lowest chloride concentration of the standard curve $(1.00 \mathrm{ppm})$ and 10 times of LOD concentration was higher than it, thus, according to ISO 8644-2 these values were accepted.

\section{Precision}

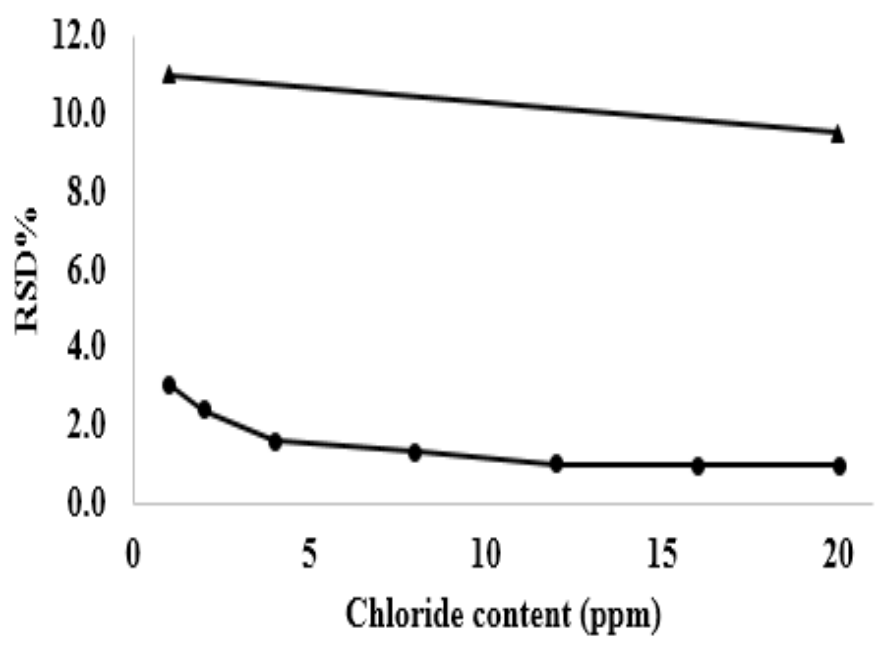

\section{-This study RSD\% -Accepted RSD\% (AOAC 2011)}

Trueness

To determine the recovery of the procedure polymer samples were spiked with known amounts of chloride and analyzed by the method. The results showed that the recoveries of the whole procedure including two steps alkaline fusion and spectrophotometric analysis were over $93 \%$ at three levels of chloride content (Fig. 3).
The standard solutions with various chloride contents from $1 \mathrm{ppm}$ to $20 \mathrm{ppm}$ were prepared and measured independently 5 times for each level. All RSD \% at different chloride levels were lower than those required by AOAC International (Fig.2) [6]. 
the analytical method complied with the international regulations.
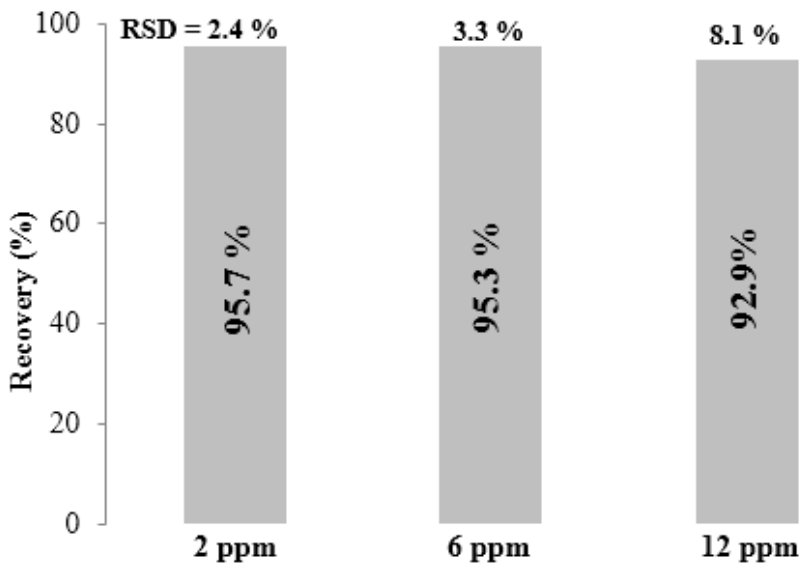

\section{Chloride Content}

Figure 3. The recoveries of the analytical procedure $(n=3)$

Monitoring the chloride content of the crosslinked polystyrene in amination process

11 real samples denoted as N0 to N10 were the starting polymer (N0) and the products (N1N10) of amination with ethylenediamine at various reaction conditions. N0 was crosslinked polystyrene containing methyl chloride groups. After the amination process, the contents of chloride in the products were decreased while an increase of $\mathrm{N} \%$ was observed. The sum of residual chloride and the ones converted to amine groups were somewhat lower than the chloride in the starting material indicated that beside the amination there were other reactions taken place on the active methyl chloride group e.g. hydrolysis to form hydroxyl.

Table 2. Result of the chloride and nitrogen content in real polymeric material

\begin{tabular}{llllll}
\hline Sample No. & Cl $(\%)$ & N $(\%)^{*}$ & Sample No. & Cl $(\%)$ & N $(\%)^{*}$ \\
\hline N0 & 13.4 & 0 & N6 & 1.5 & 6.5 \\
N1 & 7.2 & 3.8 & N7 & 3.9 & 6.3 \\
N2 & 2.4 & 5.4 & N8 & 1.4 & 6.6 \\
N3 & 4.6 & 5.2 & N9 & 2.7 & 6.0 \\
N4 & 2.0 & 5.7 & N10 & 3.3 & 5.8 \\
N5 & 5.1 & 5.5 & & & \\
\hline \multicolumn{7}{c}{$(*) N$ was determined by Kjeldahl method. }
\end{tabular}

\section{CONCLUSIONS}

In this work, the simple and accurate analytical method for determination of the content of chloride in polymeric samples was developed and validated. With high recoveries and low limit of quantitation the developed method is a simple and effective tool in studying modification processes of chloride-containing polymers for preparation of polymers with variety of functional groups. 


\section{Phát triển và thẩm định phương pháp phổ hấp thu phân tử ứng dụng định lượng chloride trong vật liệu polymer}

- Huỳnh Minh Châu

- Nguyễn Thảo Nguyên

- Võ Đình Thiên Vũ

- Nguyễn Ánh Mai

Trường Đại học Khoa học Tự nhiên, ĐHQG-HCM

\section{TÓM TÁT}

Một phương pháp phân tích đơn giản được phát triển để xác định hàm lượng chloride trong các loại vật liệu polymer. Quy trình gồm có hai bước, đầu tiên mẫu polymer được hòa tan bằng phương pháp kiềm chảy tiếp đó là lượng chloride được xác định thông qua việc đo mật độ quang của phức $\mathrm{Fe}(\mathrm{SCN})^{2+}$ tại bước sóng $460 \mathrm{~nm}$. Phức này được hình thành từ phản úng giữa chloride, thủy ngân (II) thyocyanate và ion sắt (III).

Đường chuẩn dạng phi tuyến được xây dựng trong khoảng nồng độ từ 0,5 đến 20 ppm với hệ số $R^{2}=0,9991$; giới hạn phát hiện và giới hạn định lượng lần lượt là 0,325 và 1,083 ppm. Hiệu suất thu hồi của toàn quy trình lớn hơn 92,9\% với RSD 2,4\%. Phương pháp này được ứng dụng để xác định sự biến đổi hàm lượng chloride trong quá trình amine hóa vật liệu poly(divinylbenzene-co-vinyl benzyl chloride).

Từ khoá: Polymer khâu mạng, kiềm chảy, phân tích phổ hấp thu phân tử gián tiếp, ion chloride, thủy ngân (II) thiocyanate, ion sắt (III).

\section{REFERENCES}

[1]. R. Rodrigo, C. Toro, J. Cuellar, Preparation of chloromethylated and aminated gel-type poly(styrene-co-divinyl benzene)micropartic les with controlled degree of functionalization, J. Appl. Polym. Sci., 130, 4054-4065 (2013).

[2]. R. Praveen, G. Naidu, T. Rao, Dithiocarbamate functionalized or surface sorbed Merrifield resin beads as column materials for on line flow injection-flame atomic absorption spectrometry determination of lead, Anal. Chim. Acta., 600, 205-213 (2007).

[3]. D. Fuente, B. Chico, M. Morcillo, A SEM/XPS/SKP study on the distribution of chlorides in contaminated rusty steel, Corros. Sci., 48, 2304-2316 (2005).

[4]. Y. Tang, X. Ma, Z. Lai, D. Zhou, Y. Chen, Thermal gravimetric characteristics and combustion emissions of rubbers and polyvinyl chloride in $\mathrm{N}_{2} / \mathrm{O}_{2}$ and $\mathrm{CO}_{2} / \mathrm{O}_{2}$ atmosphere, Fuel, 104, 508-514 (2013).

[5]. H. M. Chau, N. A. Mai, Synthesis of hypercrosslinked polystyrene used as sorbent for determination of volatile organic compounds in gaseous samples, J. Chem., T51, 91-94 (2013). 
[6]. Standard Format and Guidance for AOAC Standard Method Performance Requirement, AOAC International (2011).
[7]. T. Crompton, Polymer Reference Book, Chapter 2: Non-metallic Elements, Rapra Technologies Limited, 64-65 (2006). 